Article

\title{
Grid Load Reduction through Optimized PV Power Utilization in Intermittent Grids Using a Low-Cost Hardware Platform
}

\author{
Mashood Nasir ${ }^{1, *(0)}$, Hassan Abbas Khan ${ }^{1}{ }^{\mathbb{D}}$, Irfan Khan ${ }^{2, *}$, Naveed ul Hassan ${ }^{1}{ }^{\mathbb{D}}$, \\ Nauman Ahmad Zaffar ${ }^{1}$, Aneeq Mehmood ${ }^{3}$, Thilo Sauter ${ }^{3}$ and S. M. Muyeen ${ }^{4}$ (D) \\ 1 Department of Electrical Engineering, School of Science and Engineering, Lahore University of Management \\ Sciences (LUMS), Lahore 54792, Pakistan; hassan.khan@lums.edu.pk (H.A.K.); \\ naveed.hassan@lums.edu.pk (N.u.H.); nauman.zaffar@lums.edu.pk (N.A.Z.) \\ 2 Department of Marine Engineering Technology in a joint appointment with Electrical and Computer \\ Engineering, Texas A\&M University, Galveston, TX 77554, USA \\ 3 Center for Integrated Sensor Systems, Faculty of Health and Medicine, Danube University Krems, Krems \\ 3500, Austria; its.aneeq@gmail.com (A.M.); thilo.sauter@donau-uni.ac.at (T.S.) \\ 4 Department of Electrical and Computer Engineering, Faculty of Science \& Engineering, Curtin University, \\ Perth 6845, Australia; sm.muyeen@curtin.edu.au \\ * Correspondence: mashood.nasir@lums.edu.pk (M.N.); irfankhan@tamu.edu (I.K.)
}

Received: 13 April 2019; Accepted: 6 May 2019; Published: 9 May 2019

\begin{abstract}
Renewable energy incorporation in many countries takes different forms. In many developed countries, grid-tied solar photovoltaic (PV) installations are widely coupled with lucrative Feed-in-Tariffs (FiT). However, conventional grid-tied solutions are not readily viable in many developing countries mainly due to intermittent grids with load shedding and, in some cases, lack of net-metering or FiT. Load shedding refers to an intentional electrical power shutdown by the utility company where electricity delivery is stopped for non-overlapping periods of time over different parts of the distribution region. This results in a non-continuous availability of the utility grid for many consumers over the course of a day. In this work, the key challenges in the integration of solar energy explicitly in residential power back-up units are reviewed and system hardware level requirements to allow optimized solar PV utilization in such intermittent grid environments are analyzed. Further, based upon the low-cost sensing and real-time monitoring scheme, an online optimization framework enabling efficient solar incorporation in existing systems to achieve minimum grid dependence in intermittent grid environments is also provided. This work is particularly targeted for over 1.5 billion residents of semi-electrified regions in South Asia and Africa with the weak and intermittent grid.
\end{abstract}

Keywords: optimal planning; solar UPS; hardware platform; intermittent grids; load shedding

\section{Introduction}

The increasing awareness along with environmental concerns has resulted in concentrated efforts towards renewable energy incorporation. As $60 \%$ of the global electricity production is still dependent on fossil fuels [1], the goal has been to fulfill the world's increasing demand for electricity from local and clean energy sources such as solar PV for both grid-connected and off-grid communities [2-5]. To expedite this process, subsidies and lucrative Feed-in-Tariffs (FiT) have been introduced in many developed countries which have resulted in large grid interconnections through wind farms or solar photovoltaic (PV) plants [6-8]. At the same time, a lot of research has been conducted for the incorporation of this clean energy into the grid, designing smart grids and energy optimization techniques in stable grids [9-12]. Typically, a smart grid is an addition to the existing power system that 
enables real-time communication and control between the consumer and the utility. It allows power suppliers and consumers to optimize power usage based on price preferences, and environmental and technical issues of the system. The smart grid utilizes IT technologies to communicate the power demands of the loads status to the generating station by using either power line communication or various wired/wireless technologies [13].

A basic motivation behind building a smart grid is efficient management of peak demand. The major pre-requisite for that is the availability of a stable grid that is able to supply power continuously to the loads. This is not the case in developing countries in Asia, Africa and Latin America where electricity demand has risen sharply to sustain the economic growth [14]. These countries are still largely relying on fossil fuel to meet their energy demands. However, due to diverse factors such as rapid economic growth, fluctuating prices of crude oil, global meteorological effects, political uncertainties, etc., the electricity needs of users in these countries are not completely met [15]. The difference between electricity demand and supply is termed as 'electricity shortfall'. The electricity shortfall is not constant and fluctuates over the course of time. For example, it is affected by seasonal variations and is generally higher in summers when the demand is at its peak mostly due to air-conditioning loads [15]. This difference between peak demand and supply is termed as peak electricity shortfall. Many countries in South Asia (which houses 25\% of the world's population) are not self-sufficient in meeting their peak electricity demands and this peak electricity shortfall could be very significant. For instance, the recorder peak shortfalls are around $\sim 53 \%$ in Nepal, $\sim 32 \%$ in Pakistan and $\sim 10 \%$ in Bangladesh and India $[16,17]$.

Hence, to 'curb' demand and reduce the load on the grid, rolling blackouts or planned load shedding are introduced. This is basically an intentional electrical power shutdown by the utility company where electricity delivery is stopped for non-overlapping periods of time over different parts of the distribution region. This results in a non-continuous supply of electricity to those regions over the course of a day. Such a grid is termed an 'intermittent grid'. Governments in many developing countries have also introduced price-based tariff schemes to lower the peak demand $[18,19]$. However, the overall demand in many countries is still considerably higher than the overall supply. More often than not, blackouts are introduced in urban (domestic) and rural areas to route power towards industrial regions, thus affecting the residential population and small suburban industries [20]. This results in reduced economic growth with many constraints on growth and productivity.

The scheduled (and unscheduled) load shedding amount and pattern generally vary in rural and urban areas. Similarly, industrial consumers also have specific load shedding patterns to plan their activities accordingly. For example, in Pakistan, the load shedding pattern for urban areas ranges from 6 to $8 \mathrm{~h}$ [18], while in rural areas the scheduled outage varies from 10 to $14 \mathrm{~h} /$ day [21]. Another study on load shedding in urban areas of India shows (for 73 days of measured data) a load shedding average of approx. 3-4 h/day [22]. Similarly, in Bangladesh, load shedding hours for urban areas vary from 3 to $4 \mathrm{~h} /$ day and for rural areas, load shedding hours vary from 8 to $10 \mathrm{~h} /$ day [23].

Substantial work for both research and implementation aspects of demand monitoring and renewable integration has already been reported for developed countries [24-32]. For instance, Numbi et al. [24] presented an optimal energy control of a $3 \mathrm{~kW}$ residential grid-interactive solar PV system and studied the effects of varying feed-in-tariffs on the profitability of the system. The model presented in [24] is not valid for the case of developing countries where feed-in-tariff is not offered by the utilities due to grid intermittency and regular grid outages. Similarly, Bananeh Ansari et al. [25] proposed a framework for optimal PV integration into the grid, considering the optimal size and dispatch of end-user-owned battery with the objective of minimizing the end user's energy bill in a net-metering environment. The model presented in [25] accounts for battery degradation and tends to maximize the PV utilization, however, cannot be directly applied to the scenario of developing countries where net-metering is not possible due to the intermittent availability of the grid. Similarly, an overview of various optimal energy management systems considering residential scale PV grid integration has been presented in [26,27]. However, all of these models consider either net-metering or feed-in-tariff 
for optimal PV utilization, which in the case of developing countries are not applicable. Similarly, Zong Woo Geem et al. [28] presented a harmony search algorithm for optimal charge scheduling of an energy storage system (ESS) with renewable power generators e.g., PV, under time-of-use pricing. However, the proposed algorithm relies on prediction algorithms for grid energy cost minimization without measuring actual incident irradiance or load on the system. Similarly, various forecasting-based linear and non-linear optimization models for residential energy management systems have been proposed in [29-32]. Chao Sun et al. [31] showed that economic performance of a PV/battery based residential energy management system is a function of forecast error and optimized economic performance can be achieved by minimizing forecasting errors for solar irradiance and building load. Accurate load forecasting, through advanced forecasting algorithms, allows optimal scheduling of generation resources as well as optimal charging and discharging of battery storage systems. Since battery aging is directly affected by its charging and discharging patterns, thereby an accurate load forecast allows the battery to be charged or discharged according to the future load requirements with minimal overcharging and deep discharging events, thereby, enhances its lifetime. In [31], authors proposed that by using a non-linear model predictive based (MPC) control capable of closing the gap between building energy management formulations, advanced load forecasting techniques, and nonlinear battery/PV models, the economic performance of building management system can be enhanced in terms of longevity of the battery storage system. Authors showed that MPC in conjunction with robust forecasting algorithms and accurate PV/battery models can achieve close to $98 \%$ of the optimal offline performance with a $25 \%$ increase in battery life. Therefore, using an accurate forecasting algorithm allows system performance to be maintained while economic performance is enhanced.

Alternatively, in this work, we have presented a low-cost hardware platform for efficient incorporation of Solar PV in intermittent grids that comprise of (a) low-cost sensing, (b) real-time monitoring and (c) intelligent decision making based upon an online optimization algorithm. The low-cost hardware platform ensures efficient PV utilization and is valid for the scenario of developing countries where feed-in-tariff and net metering facilities are generally unavailable. The online algorithm is based upon the simplistic assumption of previous day irradiance data and does not consider the uncertainty of incident irradiance. The simplicity of the online algorithm allows performance enhancement with minimal computing resources. Alternatively, advanced forecasting algorithms such as rolling window techniques, capable of considering the effect of uncertainty can be employed for better gains in performance, however, the inclusion of complex forecasting method will increase the complexity and cost of the hardware. Therefore, an optimization of cost, complexity, and gains in performance is crucial for better resource utilization. The proposed low-cost hardware platform allows efficient incorporation of PV in the residential building with intermittent grid supply availability. Therefore, the proposed solution adds to the literature in terms of energy reliability, electricity access, energy efficiency, energy optimization and soft computing along with PV and battery storage technologies [33-36]. Moreover, in the global context, this method is applicable for feed-in-tariff, optimal battery charging and discharging as well as peak shaving for the varying time of usage (TOU) tariff $[37,38]$.

The rest of the paper is structured as follows. Section 2 presents an overview of the proposed system architecture which is capable of incorporating solar PV for not only battery charging but also for actively driving the loads (for optimum operation). It also introduces the formulation of the mathematical framework suitable for efficient system operation. Section 3 shows the results for system performance in terms of lowering grid utilization compared to conventional alternative along with quantification of overall gains in various load shedding scenarios. Section 4 addresses common challenges for the implementation of these systems in typical settings with elaborating a need for retrofitting solutions incorporating the presented functionality. This section also discusses the main challenges with storage (as a key bottleneck) for many of the backup applications. Section 5 concludes the work with outlining typical energy savings for a common consumer in developing regions. 


\section{Motivation, Problem Statement, and Contributions}

Although solar energy is abundantly available in many developing countries, their induction through conventional grid-tied topologies (without storage) is of little relevance as the demand to drive critical load is not met during grid outages. Thus, Uninterruptable Power Supplies (UPS) for critical loads are commonly seen. Figure 1 shows various modes of operation of such a setup at day and night time. A typical block level diagram showing the grid, solar PV and battery powered by UPS during daytime is given in Figure 1a. In a scenario where the grid is unavailable during the day time, solar panels along with storage powers up the loads (Figure 1b). Night time operation involves storage in addition to the grid ensuring that the load demand is met (see Figure 1c,d). Figure 1c,d also includes conventional UPS operation where solar PV provision is not available. Based on typical use-case scenarios shown in Figure 1, it can be seen that conventional UPS systems are originally designed to provide backups when the grid is unavailable. The batteries are charged through the grid (if available) while there is no inherent provision of adding a supplement energy source $[16,18]$.

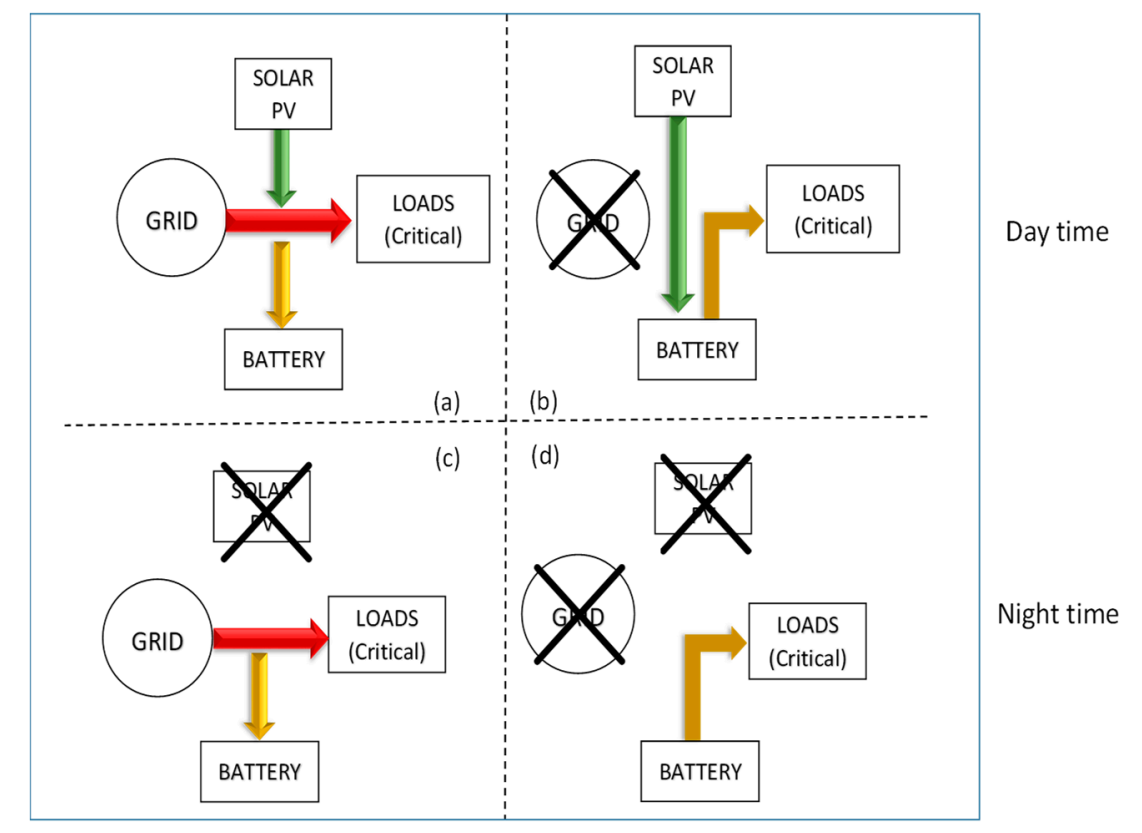

Figure 1. (a) Typical power flow diagram for a residential house with photovoltaic (PV) integrated into backup settings. (b) Day time operation with grid unavailable. (c) Night time operation with grid available. (d) Night time operation with grid unavailable.

Charging of batteries in these settings through solar panels is only available through maximum power point tracking (MPPT) charge controllers which can readily be integrated with batteries $[39,40]$. However, the direct addition of solar power in UPS settings is largely suboptimal. This is due to the inherent operation of conventional UPS in which the utility power is used for both feeding the critical load and charging the battery when the grid is available, and the available solar PV output can only supplement the battery charging [39]. The main problem with this implementation is that once the battery is fully charged, the available solar resources undergo wastage during grid availability hours. Further, for grids in many developing countries, back feeding to the utility is often not allowed (due to government regulations to ensure stability or minimize electricity theft) or the capability is often not available in UPS systems. Therefore, the only option is to use the solar PV for charging the battery, and limited battery storage capacity and lower load shedding diminishes the overall utilization of available PV resources.

For the optimized operation of solar-assisted home power back-up systems, the use of solar PV should not only be limited to charge the batteries; first and foremost, it should be used to drive the 
load in conjunction with the grid along with charging the battery when surplus solar is available. Therefore, a cost-effective system architecture is proposed in this work which is not only capable of an efficient source switching mechanism but also with real-time intelligent decision making on the charging and discharging of the storage. Various critical parameters that affect the incorporation of solar PV in intermittent grids are identified and analyzed for maximum solar intake. Hence, our first contribution lies in the identification of smart solar powered system architecture which is best suited for UPS applications for developing countries with intermittent grids. The focus is limited to UPS environments where back feeding is not considered due to policy and infrastructural issues.

Our second and main contribution lies in the formulation of an online optimization framework based upon a low-cost hardware platform consisting of low-cost sensing and real-time monitoring schemes for optimized system operation to minimize grid power intake while satisfying all the load requirements, battery state-of-charge requirements and incorporation of grid intermittence. This will be highly beneficial in overall cost minimization where efficient utilization of solar panels and optimum system operation would minimize the system costs reducing the first-time entry barrier for many consumers in developing countries with lower incomes. We further analyze the proposed system with the optimization framework for a yearlong system performance evaluation to quantify the overall gains (reduction in the grid utilization) under different intermittence rates.

It must be noted that this work is only targeted for increased solar intake in developing countries with load shedding and is only best optimized for UPS settings. The proposed methodology may not be optimal for typical building-level energy optimization in many advanced countries where smart meters are added so that back-feeding to the grid is prioritized based on tariffs. Highly sophisticated grid-tied solar solutions (with or without storage) for developed countries are readily available through major companies like Schneider [41], SMA [42] and others [43]. Numerous other solutions for developing regions are typically UPS solutions with no built-in capability of solar intake or no optimal framework for most efficient operation [44]. The proposed system is, therefore, the best fit for optimized utilization of available PV resources and reduced dependence upon the grid for consumers in many developing regions with intermittent grids.

\section{The Low-Cost Hardware Platform for Efficient Incorporation of Solar PV in Intermittent Grids}

The low-cost hardware platform for efficient incorporation of Solar PV in intermittent grids comprises of (a) low-cost sensing, (b) real-time monitoring and (c) intelligent decision making based upon an online optimization algorithm. Figure 2 provides such a modified system architecture which is capable of incorporating solar PV for not only battery charging but also for actively driving the loads. Moreover, there is also an additional provision of optimized battery charging from utility based upon the information of load shedding pattern, solar irradiance availability and battery state of charge.

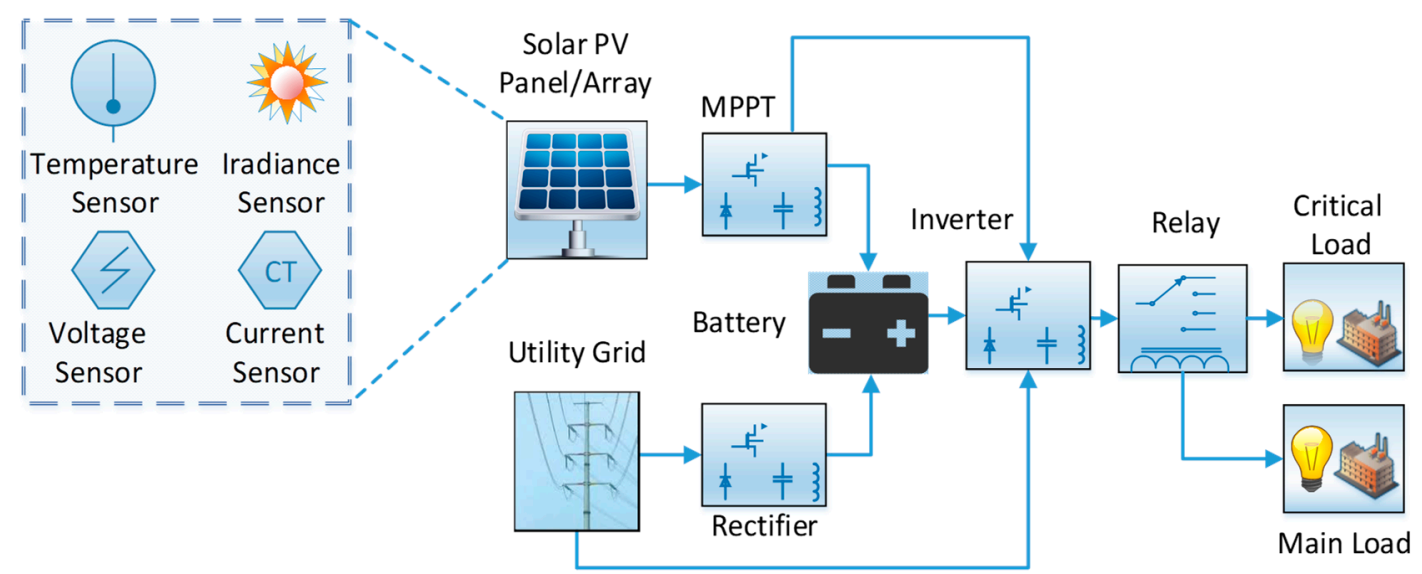

Figure 2. Proposed architecture for solar PV integration in intermittent grids. 
The purpose of the relay in Figure 2 is to switch between normal and critical loads based upon the availability/unavailability of the grid. The grid-tied inverter is responsible for accumulating PV and grid power for satisfying the critical load demand simultaneously. The extended functionality is achieved through the intelligent decision making through an online algorithm fed in the processor which decides optimized power flow from the grid to load, grid to the battery, and battery to load, solar to load and solar to the battery based upon real-time sensed parameters mainly including PV generation and incident load. This functionality otherwise is not available in the existing off the shelf UPS back-up systems in the markets of developing countries. Further, sensing of available PV power through temperature and irradiance sensors is also an extended functionality which is not available in existing UPS solutions.

The power output from the solar panel(s) is maximized through an MPPT converter, which has the output directly connected to the battery. While various MPPT units are available, the incorporation of cost-effective irradiance and temperature sensors are also required for efficient system monitoring. This allows (a) enhancing the panel performance and (b) pre-emptive maintenance in case of failing system components. In Section 2.1, we elaborate on the design of these sensors capable of monitoring irradiance and temperature even for low-end domestic consumers.

There is a possibility of PV power curtailment when PV generation increases from battery storage and critical load requirements. However, this will be very rare in a practical UPS system as PV generation and battery storage is sized based upon the load shedding pattern and critical load demand which in general is much higher in comparison to PV generation most of the time. Since scheduled load shedding patterns are generally announced by the utility companies, and critical load requirements are known to the users, therefore, PV generation and batteries may be sized to ensure minimum curtailment of PV power. The emphasis of the work here is a framework for an optimized PV incorporation in UPS backup systems with weak grids in many developing countries, therefore, the main point of concern is the fulfillment of critical loads rather than an overall load of the system. Alternately, in a scenario, where PV generation is kept relatively higher, then, there should be a provision of feeding back to the main load for maximum resource utilization. In addition to monitoring of solar input and ambient parameters, the following information is required to design any optimization strategy, which will ensure optimized incorporation of solar PV in intermittent grids:

- State of the grid and intermittence pattern

- State of storage and captive generation (if available)

- Load switching capability of the relay for optimum operation

Figure 3 shows the involvement of these parameters in the proposed system design. The intermittence pattern and power outage information are often distributed to the public beforehand. The state of the solar PV array, battery, critical loads and relay capability can be handed over from their respective blocks during run-time to the central processor. The processor itself can be supplied with a backup battery to avoid system shutdown during grid-power outages. Based upon grid intermittence, state of battery and irradiance, an optimization strategy can be used to perform optimum switching between solar PV, grid utility, and the battery through the relay to ensure the efficient utilization of the available energy resources. Moreover, decisions about charging or discharging for the battery can also be made based upon the optimized decision variables.

The pre-known information of load shedding schedule can be stored in the online algorithm and the proposed hardware platform may be configured accordingly. Any instant of load shedding other than scheduled one will not be stored in the proposed framework; therefore, the system will detect it as a non-scheduled load shedding duration and behave like a conventional battery-based backup system without performing any optimized operation. If the pattern of load shedding is unknown, then load demand constraints will be violated and solution to the optimization program has the tendency to become infeasible. Therefore, the optimized operation can be obtained only if the information of the load shedding schedule is available and the hardware platform is configured accordingly. Thus, an 
efficient system design with all these functionalities/capabilities will be key to ensuring active solar PV incorporation for critical loads in regions with intermittent grids.

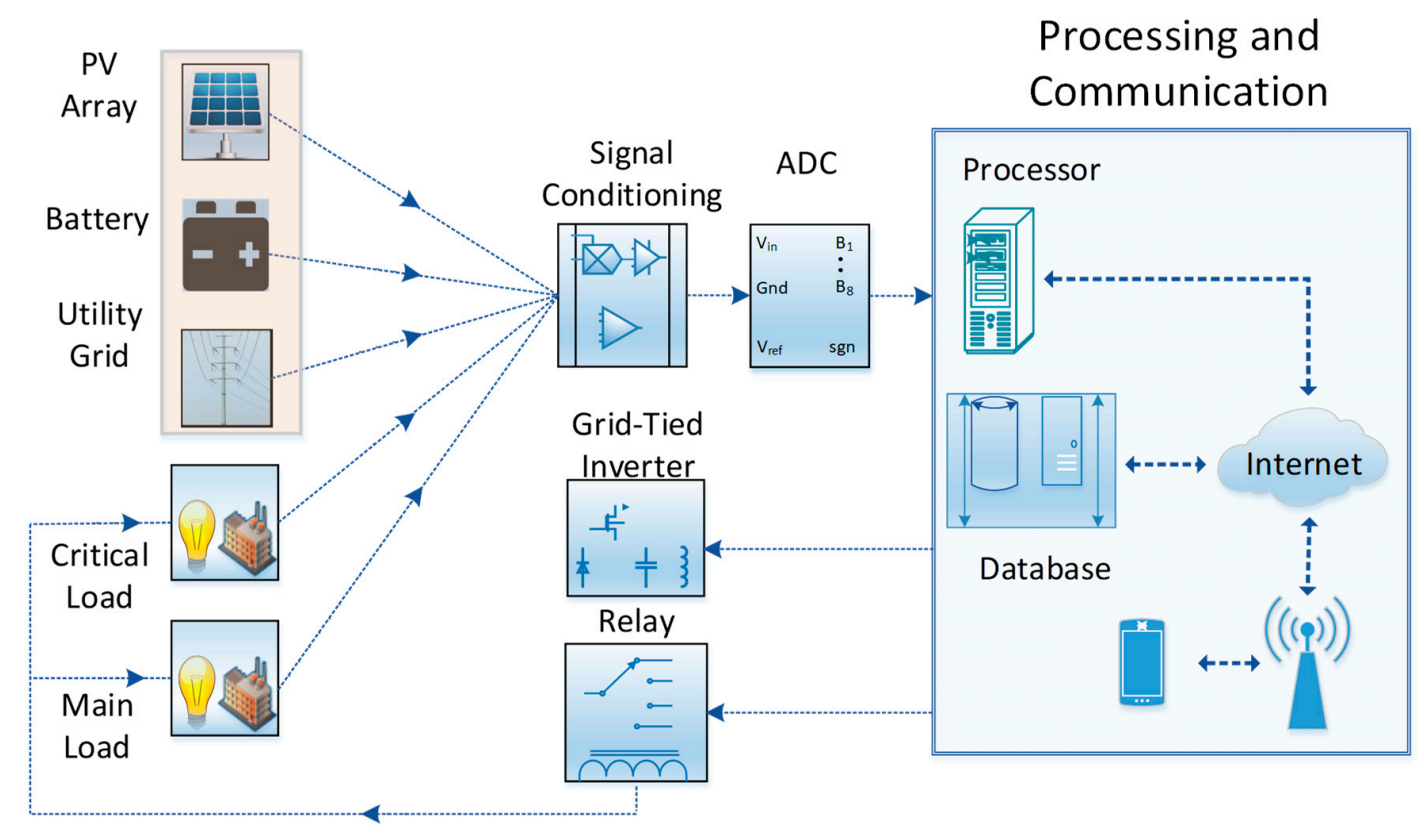

Figure 3. Block diagram showing communication between processor various power sources and controlling of the relay.

\subsection{Sensing and Instrumentation}

Instrumentation plays an important role in monitoring the power generated through sunlight and processed through converters. This is critical in ascertaining the performance of the PV system along with scheduling of pre-emptive maintenance [45], which results in the better evaluation of the system and increases consumer confidence for these long-term energy investments. It should be noted that various suboptimal solar implementations result in a lack of consumer confidence in developing countries resulting in the creation of an additional social barrier for general solar PV uptake [46]. Therefore, among other parameters, measurement of irradiance and panel surface temperature are very useful to assess the performance ratio of the system, and they are discussed below.

\subsubsection{Module Temperature Measurement}

It is well established that the performance of a solar panel degrades with increasing temperature [47]. Solar cells inside a module are covered in glass to protect them from the environment which results in a significant temperature gradient between a module and the ambiance, particularly in warmer regions. In addition to the heat emitted by solar cells (due to high energy photons), the glass traps infrared radiation in the sunlight that further increases the module's temperature. Generally, two methods are used to assess the cell temperatures which are (a) direct module temperature measurement and (b) estimation through ambient temperature $T_{a m b}$ using solar insolation level $(S)$ in $\mathrm{mW} / \mathrm{m}^{2}$ and module's nominal operating temperature $T_{N O C}$. The solar cell temperature can thus be calculated as [48]:

$$
T_{\text {cell }}=T_{a m b}+\left(\frac{T_{N O C}-20}{80}\right) S .
$$

The temperature dependent degradation in power output can be estimated through Equation (1) by taking into account the negative temperature coefficients for a particular solar PV material system. For instance, the degradation in the power output for the c-Si panel is taken to be around $-0.44 \%$ to $-0.48 \%$ per degree rise in temperature above $25^{\circ} \mathrm{C}$ [46]. However, the direct measurements are 
a more reliable method compared to indirect measurements of temperature as shown in Figure $4 \mathrm{a}$. The variances between measured and predicted temperature can be high and therefore direct panel temperature measurement techniques should be used in these settings. The availability of temperature information can be critical in terms of pre-emptive maintenance, optimizing cleaning schedules and mitigation of mismatches, shading, possible hotspots and other undesired phenomena in solar PV systems, even for low-end domestic consumers.

Fig. 4 (a)

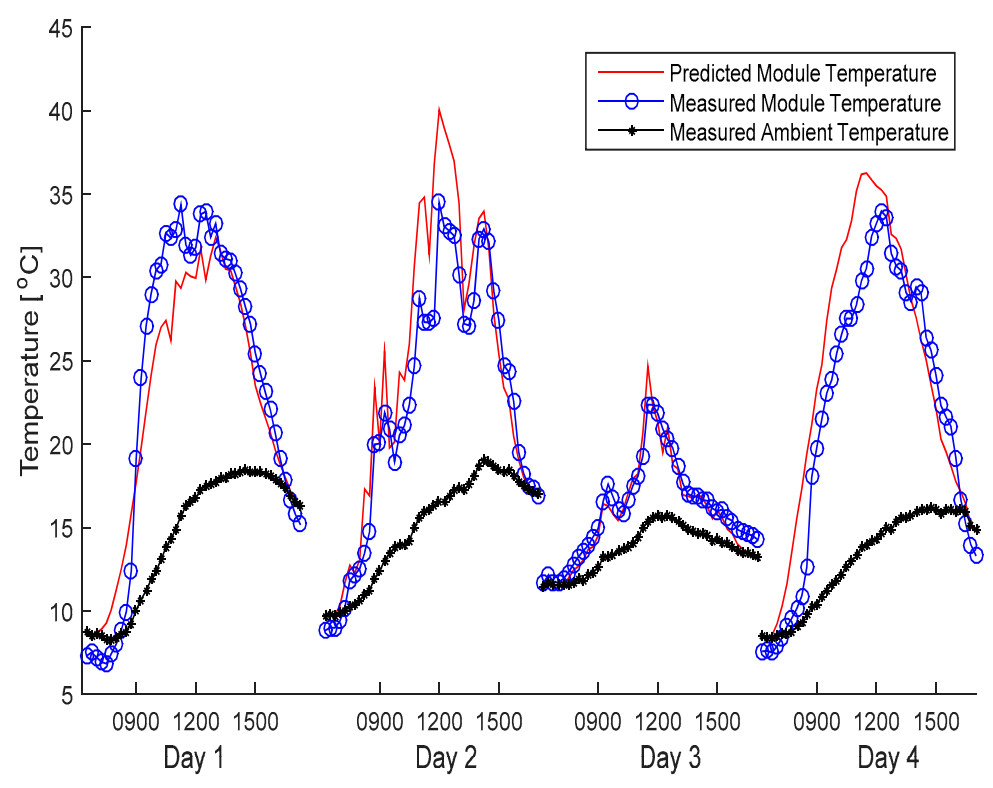

Fig. 4 (b)

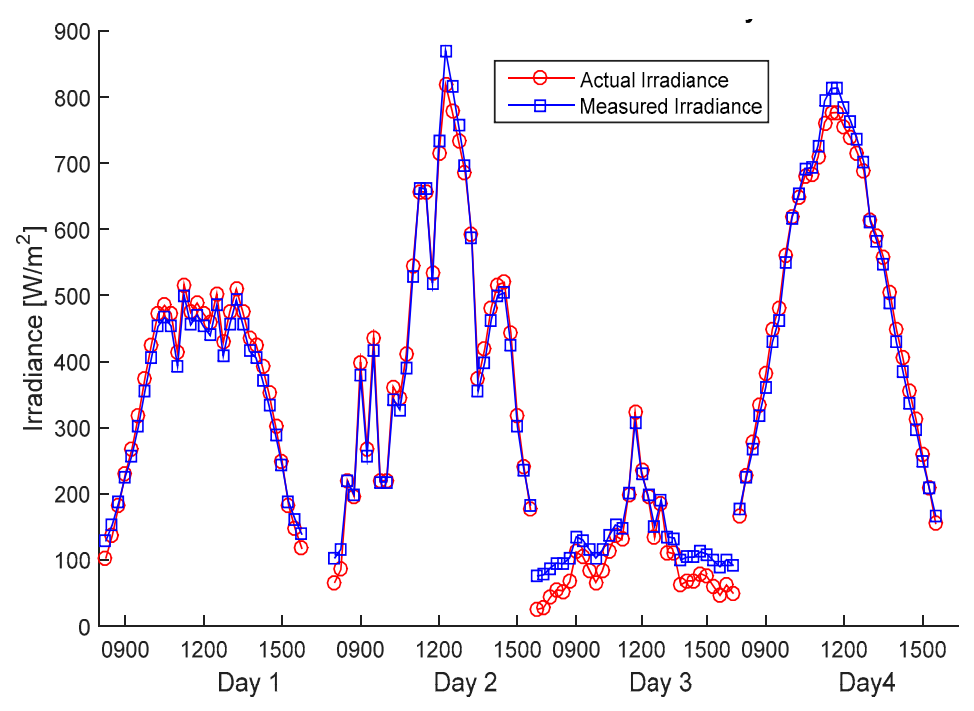

Figure 4. Comparison between measured and predicted values for four days for installation at Lahore, Pakistan. (a) Temperature comparison, (b) Irradiance comparison. 


\subsubsection{Irradiance Sensor}

Solar irradiance monitoring is essential to assess the long-term performance of a PV system. Typically, instruments such as pyranometers and pyrheliometers are used for local irradiance measurements $[49,50]$ which add considerable cost to the system.

The accurate irradiance estimation through indirect methods [51] may not be very reliable for regions with partial shading and frequent cloud covers. Local measurement of solar irradiance is therefore required for detailed performance evaluation of various components of the system along with accurate energy estimations, maintaining cleaning routines and for pre-emptive maintenance of some of the Balance of System (BOS) components. One method for cost-effective monitoring is presented in our earlier work [52], which is based on a simple idea that the power output of the solar panel increases almost linearly with the increase in solar radiation intensity and vice versa. The photo-voltage produced by the panel is a logarithmic function of radiation intensity whereas the current varies linearly. Thus, a small wattage solar panel can accurately estimate the solar irradiation intensity in a short circuit mode. The measured data for four days shows a close match between our method compared to commercial counterparts as shown in Figure 4b. Further details about this implementation can be seen in our earlier work [52].

\subsection{Problem Formulation for Minimization of Grid Power Intake}

Based on the optimum system shown in Figure 2, the block diagram depicting the energy flow for optimization problem formulation is shown in Figure 5. In the figure, $P_{G L}(t)$ corresponds to the power flow from grid to load, $P_{G B}(t)$ is the power flow from grid to battery, $P_{S B}(t)$ is the power flow from PV solar to battery, $P_{S L}(t)$ is the power flow from PV solar to load, $P_{B L}(t)$ is the power flow from battery to load, $G(t)$ is the power supplied by the grid, $S(t)$ is the power produced by PV panels, $d(t)$ is the load demand and the state of charge of battery within time interval $t$ is denoted by $S O C(t)$.

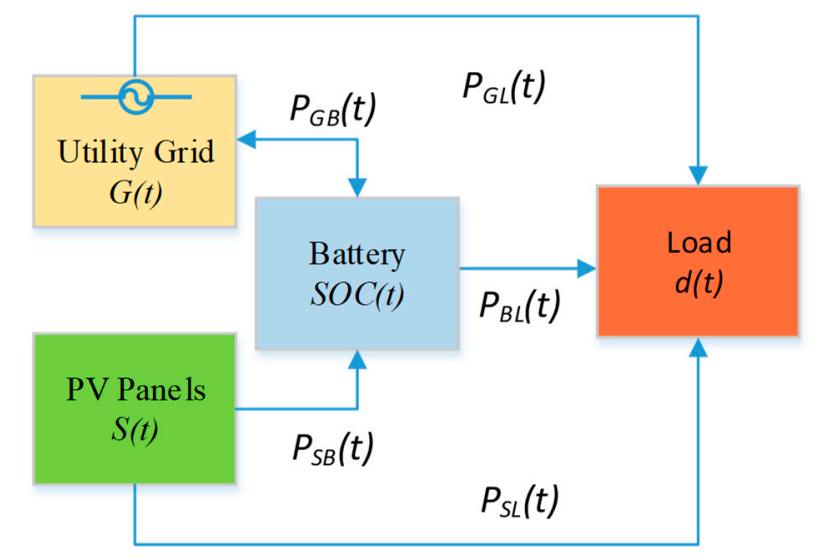

Figure 5. A block diagram for showing different actors involved in optimized grid utilization in an intermittent grid environment.

\subsubsection{Objective Function}

The objective is to minimize the grid utilization (energy units were taken from the grid) such that load demand is satisfied at all times and incident solar energy is completely utilized. The objective function is given by Equation (2):

$$
\min _{\left(P_{G L}, P_{G B}, P_{S B}, P_{S L}, P_{B L}, S O C\right)}\left[\sum_{T=0}^{T-1} P_{G L}(t)+P_{G B}(t)\right],
$$

where, $P_{G L}(t), P_{G B}(t), P_{S B}(t), P_{S L}(t), P_{B L}(t)$ and $S O C(t)$ are the decision variables that ensure optimized solar and grid utilization. 


\subsubsection{Inequality Constraints}

The decision variables are subjected to various non-negativity constraints given by Equation (3):

$$
\begin{gathered}
P_{G L}(t) \geq 0, P_{G B}(t) \geq 0, P_{S B}(t) \geq 0, \\
P_{S L}(t) \geq 0, P_{B L}(t) \geq 0, \operatorname{SOC}(t) \geq 0 ; \forall \mathrm{t}
\end{gathered}
$$

In order to ensure the battery longevity, there are limits on battery state of charge (SOC) and are given by Equation (4):

$$
S O C_{\text {min }} \leq S O C(t) \leq S O C_{\text {max }} ; \forall t,
$$

where $S O C_{\min }$ and $S O C_{\max }$ are the minimum and maximum allowed $S O C$ of the battery.

During any time interval $t$, the output power from PV panels can be supplied to either battery or load and this energy balance is governed by Equation (5):

$$
P_{S L}(t)+P_{B L}(t) \leq S(t) ; \forall t .
$$

Similarly, the power extracted from the utility grid can either be supplied to charge the batteries or fulfill the load demand during any interval $t$ as shown in Equation (6):

$$
P_{G L}(t)+P_{G B}(t) \leq \mathrm{G}(\mathrm{t}) ; \forall \mathrm{t} .
$$

The constraints on the maximum power that can be supplied during any interval from the battery to fulfill the load demand depend upon battery capacity $C_{B}(\mathrm{Wh})$ and are given by Equation (7). Extracting energy beyond this limit will affect the lifetime of the battery. Therefore, to ensure the enhanced service life of the battery, maximum and minimum state of charges and the associated energy limit is shown by Equation (7):

$$
P_{B L}(t) \leq \mathrm{C}_{\mathrm{B}}\left[S O C(t)-S O C_{\min }\right] ; \forall t .
$$

Similarly, the battery has a maximum energy storage capacity based upon its watt hours rating (energy capacity given in Wh). Supplying energy more than its rated capacity may also result in overcharging and reduced battery lifetime, and hence, Equation (8) governs the maximum energy that can be supplied to the battery from the grid or solar PV during an interval $t$. Therefore, any framework on the optimum operation of UPS systems must ensure these constraints to maximize the battery life and minimize replacements costs [5].

$$
P_{S B}(t)+P_{G B}(t) \leq C_{B}\left[S O C_{\max }-S O C(t)\right] ; \forall t .
$$

\subsubsection{Equality Constraints}

The system setup ensures that through source switching mechanism, each of the available sources contributes such that the load requirements are always fulfilled. Therefore, load demand fulfillment is governed by the equality constraint given by Equation (9):

$$
P_{G L}(t)+P_{S L}(t)+P_{B L}(t)=d(t) ; \forall t
$$

The recursive equation for battery depends upon battery capacity $C_{B}(\mathrm{Wh})$, its time-varying SOC and is given by the balance of total energy dumped into the battery and total energy demanded from the battery is given by Equation (10)

$$
\operatorname{SOC}(t+1)=\operatorname{SOC}(t)+\frac{1}{\mathrm{C}_{B}}\left[P_{G B}(t)+P_{S B}(t)-P_{B L}(t)\right] ; \forall t .
$$




\subsection{Algorithm for Online Optimization Formulation}

Standard solvers (e.g., Linprog in MATLAB) are generally used for the calculation of decision variables responsible for optimized source/load scheduling to ensure optimized grid and solar energy utilization. However, standard solvers in their conventional settings are capable to perform offline optimization only and require the pre-hand availability of the data to perform optimization over the intended time horizon. For a real-time sensing and monitoring system, it is not possible to measure the future data values, therefore, an estimation based online algorithm in conjunction with standard solvers is employed for the real-time optimization in this work.

In order to perform an optimization over the time horizon of a typical day, it is divided into $T$ time intervals, where, $t$ index represents an individual time interval and may vary from $t=1,2,3,4 \ldots$ $T$. The hardware setup shown in block diagram (Figure 3 ) is capable of monitoring real-time values of various parameters including incident irradiance, temperature, battery SOC and load demand as well as has the capability to store their past values in a dedicated database. For a typical offline optimization, these parameters are generally known in advance for all $T$ intervals; therefore, running the standard optimization solver once yields the decision variable for all $T$ time slots. For practical systems such as discussed above, it is not possible to have the future information, therefore, the data vector for these parameters has to be updated and optimization has to be performed in each interval separately. In order to keep the track of intervals, an index $i$ was defined where $i$ also varies from $i=1,2,3,4$ $\ldots T$. In each time interval $i$, the data vector for parameter $X_{i}(X$ can be incident irradiance or load demand) is given by Equation (11) and will be updated based upon the online algorithm illustrated below. The proposed algorithm is given for one-day optimized operation and can be extended to the desired number of days for optimized operation.

$$
X_{i}=\left[x_{i, 1} x_{i, 2} \cdots x_{i, t} \cdots x_{i, T}\right] \in \mathfrak{R}^{1 \times T} ; \forall i=1 \cdots T,
$$

where, $x_{i, 1}, x_{i, 2} \ldots x_{i, T}$ are the individual values of the data vector $X_{i}$ for each interval $i$ and can take either the current day value measured at the $i$ th interval or previous day value at $i$ th interval stored in the database or zero based upon the algorithm presented below. In order to avoid false estimation and subsequent non-convergence problems, the value of $x_{i, t}$ at load shedding hour is assumed zero as shown by the algorithm below.

\subsection{Methodology}

The essential components of the proposed low-cost hardware platform are discussed in the above section. Using these system components, power intake from the utility for a typical household load to fulfill its daily load demand was calculated. The power intake from the grid using proposed low-cost hardware platform and the online solution was compared with two cases, i.e., (a) ideal scenario (offline solution), and (b) conventional UPS scenario. Moreover, for the presented case, solar PV consumption and the effect of varying load shedding patterns were also evaluated for the above-mentioned scenarios. The case study data, results and discussions are detailed in the next section.

\section{Case Study, Results and Discussion}

In order to analyze the performance and viability of the proposed low-cost hardware platform, the results obtained through an online algorithm were compared and benchmarked with standard offline optimization results. The offline solution considers that all the information including incident irradiance, load shedding, and incident load patterns are available pre-hand. While, the proposed online algorithm relies on cost-effective sensing, real-time monitoring and simplified assumption of last day data. In such a scenario, the online solution serves as a lower bound on the performance determined by the offline solution. This assumption of last day irradiance data is fairly simple and reasonable as within two consecutive days, solar irradiance data does not vary much [53]. The results are shown in Figures 6-8, present the following three scenarios, (a) un-optimized, (b) optimized 
through standard offline techniques and (c) optimized through the proposed online algorithm. The patterns of energy purchased from the grid and solar utilization obtained through the proposed online case closely matches with the performance bounds determined by standard offline optimization as shown in Figures 7 and 8 respectively.

The offline analysis considers the pre-hand availability of the data and applies the standard solver i.e., Linprog in MATLAB based upon the pre-hand available data to obtain the objective given by Equation (2) subject to constraints given by Equations (3)-(11). Therefore, it provides the maximum possible gains from the optimization. While, the online algorithm as shown by Algorithm 1 below uses the simplified assumption of last day irradiance data along with real-time monitoring through low-cost sensing and does not require the pre-hand availability of the data. For a typical household in developing countries with 1-3 kW normal load and 0.6-1 kW critical load, the comparative results are shown in this section. The total load (normal as well as critical) demand in $24 \mathrm{~h}$ operation is $30 \mathrm{kWh}$. The installed solar capacity is taken at $1 \mathrm{~kW}$ for a typical residential household of a developing country with limited roof capacity. This also matches the typical UPS capacity in Pakistan, where over $90 \%$ of UPS (approx. 2 million) are rated below $1 \mathrm{~kW}_{\mathrm{p}}$ [18].

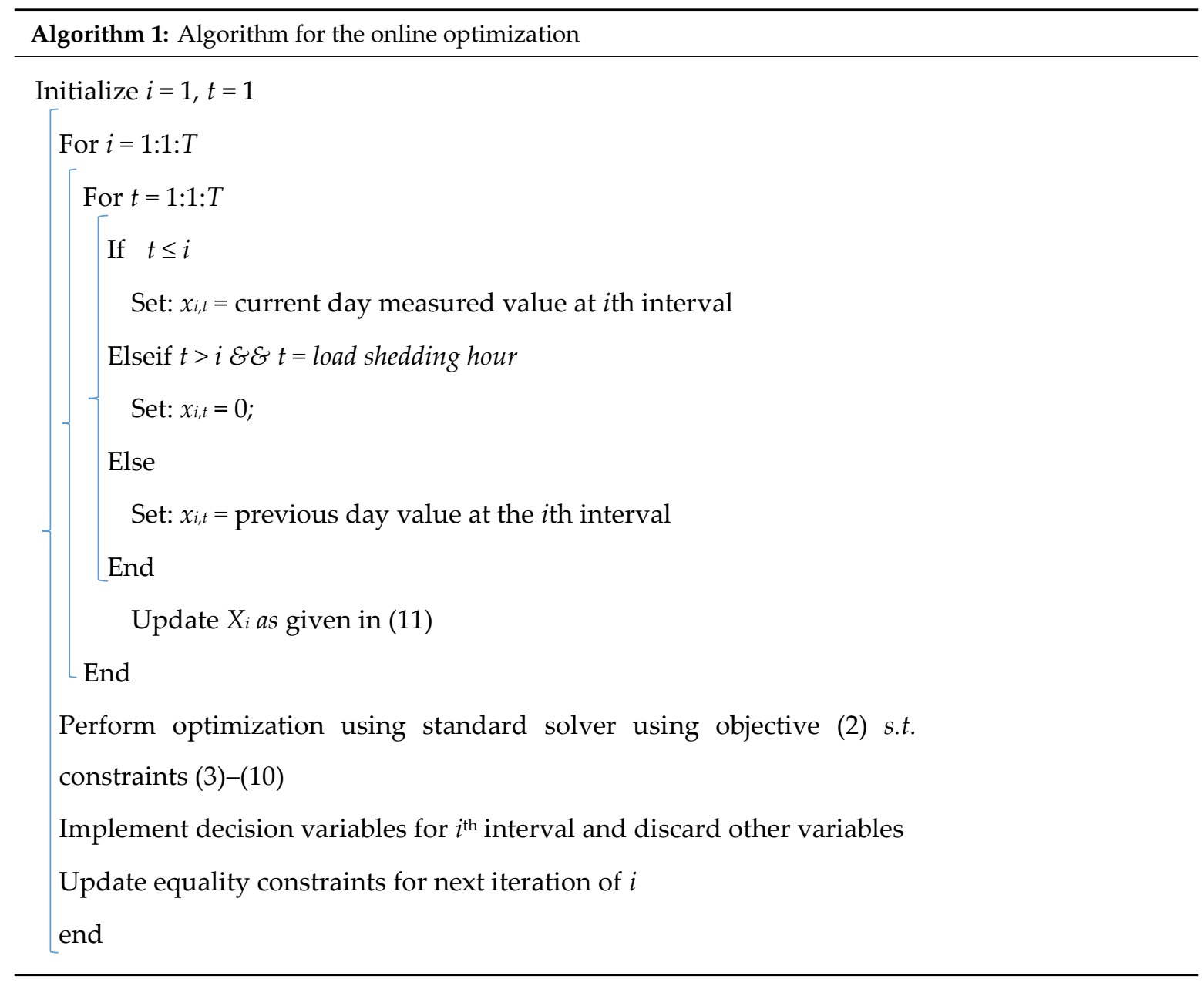

The available data of solar irradiance is taken from the National Renewable Energy Laboratory (NREL), USA, for offline analysis while estimated in accordance with the algorithm for online analysis. In addition, along with the pre-fed solar data, the local measurements can be taken by using the method described in [52]. The battery capacity for different scenarios is sized such that it can optimally store all the available PV resources and also fulfill the critical load demand at all times. An optimal planning framework for PV/battery-based electrification system has been presented in [54] which outlines the 
detailed methodology for optimal sizing along with various components that affect the optimal sizing calculations. The same concept may be extended to PV/battery-based backup systems for optimal PV size $\left(\mathrm{kW}_{\mathrm{p}}\right)$ as well as battery size $(\mathrm{kWh})$ calculation. Since scheduled load shedding patterns are generally announced by the utility companies, and critical load requirements are known to the users, therefore, batteries may be sized accordingly to fulfill the critical load requirements. Figure 6 represents the normal UPS operation for critical loads in typical PV assisted backup power installations.

Fig. 6 (a)

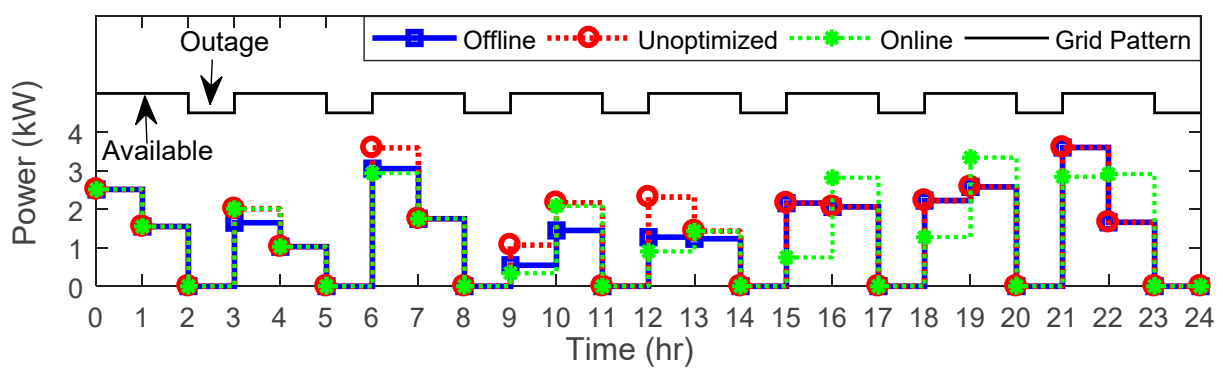

Fig. 6 (b)

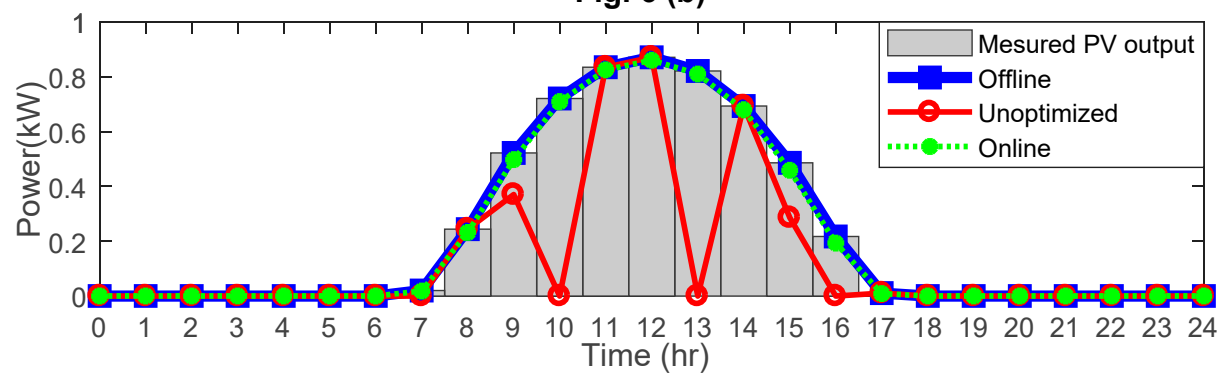

Fig. 6(c)

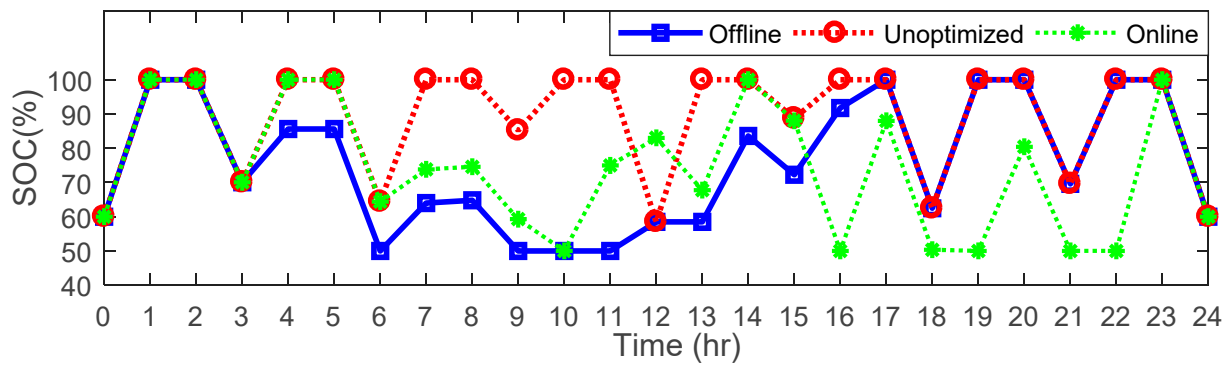

Figure 6. Comparison for Optimized and Base Case Scenario in a 24-h operation with $8 \mathrm{~h}$ of load shedding (grid unavailable). (a) Load power demand from the grid, (b) Solar Resource Utilization, (c) Battery SOC variations.

Figure 6a shows the load power demand from the grid in a typical 24-h operation with $8 \mathrm{~h}$ of load shedding (grid unavailable). Although the load shedding pattern is shown in Figure 6 is disjoint, however, there is an equal possibility of continuous outages for multiple hours rather than disjoint outages. As long as the pattern of load shedding is available, the system can be sized (PV and battery capacity sizing) accordingly to fulfill the critical load demand [54]. The proposed low-cost hardware platform has the equal ability to intelligently store the electricity in the battery for every coming load shedding hour, no matter whether these load shedding hours are disjoint or continuous. Therefore, the load shedding pattern (continuous/disjoint) does not directly affect the operation of the proposed low-cost hardware platform, rather it affects the planning and optimal sizing of the hardware platform such that with an increase in consecutive load shedding hours, despite the average number of load shedding hours in a day are the same, battery sizing tends to increase. The variability of renewable resources, due to their intermittent nature, introduces uncertainty in generation output which is generally forecasted through sophisticated prediction-based algorithms and compensated through 
battery-based buffers. In the current setup, we considered the variability of output power from solar and it is given by a time-dependent variable $S(t)$. However, in the current setup rather than using sophisticated forecasting algorithms, an online algorithm based upon cost-effective sensing, real-time monitoring and simplified assumptions of the previous day irradiance data was presented to deal with the uncertainty of intermittent PV output. Both irradiance and temperature sensors are being used for the real-time estimation of power produced by PV panels $S(t)$ at any time instant $t$. The output produced by PV panels $S(t)$ is a function of incident irradiance $I(t)$ and ambient temperature $T_{a m b}$. Due to panel losses and temperature degradations, the output of PV panel is generally lower than its nameplate capacity. Low irradiance losses generally vary linearly with the average peak sun hours (PSH) of the incident irradiance. A mathematical model to quantify low irradiance loss has been presented in [55]. Therefore, considering panel losses and the temperature degradation effect, $S(t)$ is given by Equation (12)

$$
S(t)=A \cdot \eta_{P L} \cdot \eta_{m} \cdot I_{t c}(t),
$$

where $A$ is the area of installed solar panel, $\eta_{P L}$ is the efficiency degradation due to PV panel losses, $\eta_{m}$ is PV module efficiency, and $I_{t c}$ is the temperature compensated irradiance which further depends upon the incident irradiance $I(t)$, and temperature of the cell $T_{\text {cell }}$ was given by Equations (12) and (13).

$$
\begin{gathered}
T_{\text {cell }}(t)=T_{\text {amb }}(t)+(0.01875 \times I(t)), \\
I_{t c}(t)=\left(1-\left(T_{\text {cell }}-25\right) \times 0.0045\right) I(t) .
\end{gathered}
$$

Both $T_{a m b}(t)$ and $I(t)$ are measured through low-cost sensing and then based upon Equations (12)-(14), real-time power produced by PV panels can be estimated and utilized by the online algorithm for optimized decision making. The irradiance sensor measures the incident irradiance at the start of each decision interval and hardware platform calculates the optimized decision variables accordingly based upon the sensed data, thereby, minimizing the possibility of error due to variability. Further, an assumption of zero irradiance at each load shedding interval is taken to ensure that the online algorithm converges even at higher solar variability. The resultant uncertainty due to this variability and associated assumption of zero irradiance at each load shedding interval for the proposed online algorithm results in a slightly different charging/discharging profile of the battery and power taken from the grid in comparison to the standard offline benchmarked solution as highlighted in Figure 6. The 'online' and 'offline' cases show the results from the proposed scheme where the processor minimizes the grid intake in comparison to the un-optimized case (based on system constraints discussed in the section above). It should be noted that although the grid energy intake pattern is different in both online and offline schemes, however, the sum of energy intake is more or less the same. The difference in energy intake pattern arises due to zero estimation of the irradiance at load shedding hour. If irradiance were not to be assumed zero at load shedding hour, it may lead to false optimization and subsequent non-convergence issues in the overall problem formulation. The results of optimization dictate the switching of the relays and associated converters to ensure that the power is routed optimally under the current settings. Lower utilization of grid power in the optimized case is due to a higher utilization of solar resources compared to the base case as can be seen in Figure 6b, where offline and online optimized cases are utilizing the all of the available solar resources. Overall, a huge benefit is the lower energy extraction per day from the grid as all the available PV output is being utilized resulting in significant savings.

In addition, the battery state of charge throughout the day is also shown in Figure 6c. Another important consideration is the battery SOC which is shown in Figure $6 \mathrm{c}$ for the 24-h interval. A minimum SOC level is set in accordance with battery parameters (0.5-SOC in the current set-up) and the system ensures that this is met always, even in grid outages. It is noteworthy that lead-acid SOC variation within the allowable $S O C$ levels is likely to affect battery life. However, this aspect can be further incorporated through lifetime maximization techniques [56]. 
The percentage reduction in grid power utilization for meeting the designated load demand varies with varying grid intermittence. In order to evaluate this aspect, two further scenarios with 4-h and 12-h intermittence were also analyzed and the results are shown in Figure 7. It basically shows the overall daily energy $(\mathrm{kWh})$ taken from the grid for 365-day operation for Lahore with varying grid intermittence. Each subplot shows the values for 'un-optimized case' daily electricity demand compared to the demand in an optimized scenario (both online and offline) where a significant reduction in grid dependence is observed. The offline case closely resembles with the online case for the lower value of load shedding hours ( 4 and $8 \mathrm{~h}$ ) while there is a slight difference between the offline and online case for a higher number of load shedding hours i.e., $12 \mathrm{~h}$. This difference arises from our estimation of zero irradiance at load shedding hour to avoid false optimization and subsequent non-convergence issues. As the total daily load for the case study is fixed at $30 \mathrm{kWh}$, the reduction in the grid demand (from $30 \mathrm{kWh}$ ) is due to solar incorporation which further shown in Figure 8. Figure 8 shows the solar utilization throughout the year for three grid-outage scenarios. The overall solar production for the optimized case averages around $6 \mathrm{kWh}$ for all three scenarios whereas the production per day for un-optimized, on average, is approx. 2, 3 and $4.5 \mathrm{kWh}$ for 4-, 8- and 12-h load shedding periods, respectively. The optimized scenario maximizes solar intake for all scenarios. The un-optimized case, on the other hand, shows a higher grid load reduction for higher intermittence as shown in Table 1. This is due to the reason that with the increased number of load shedding hours, the storage keeps on charging (through solar) and discharging (through the load) for higher frequency/intervals of time.

Fig.7 (a)

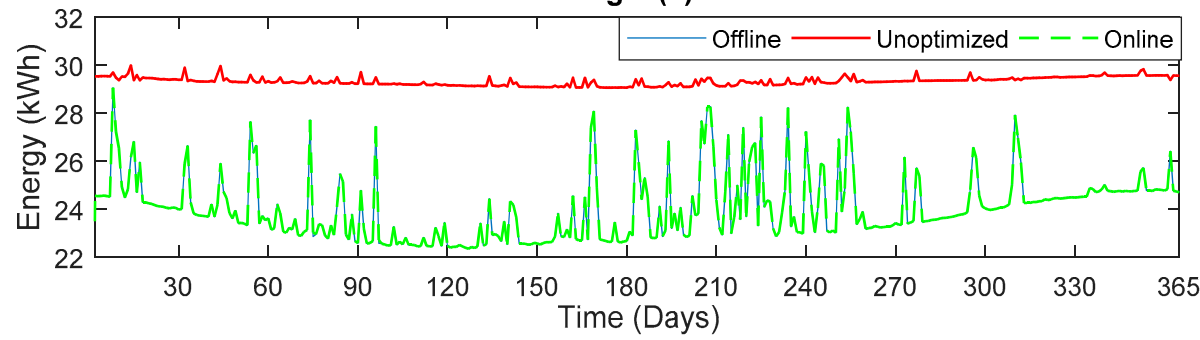

Fig. 7 (b)

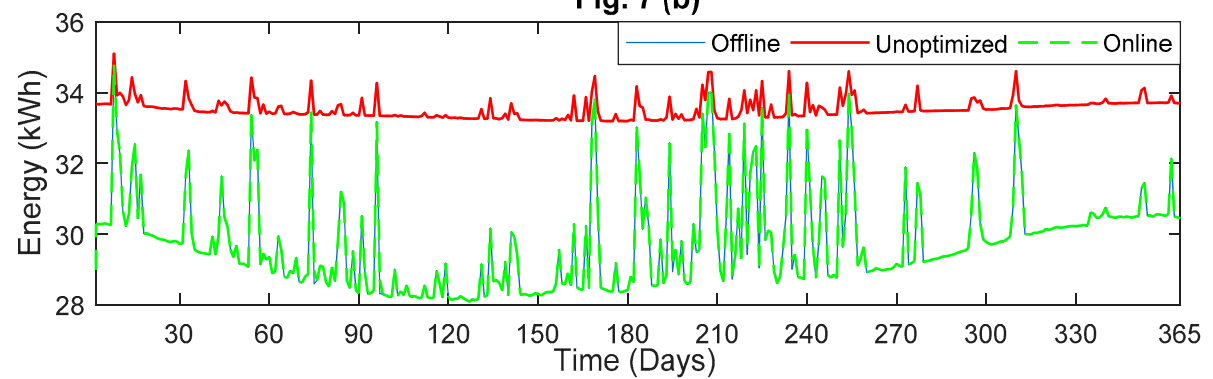

Fig. 7 (c)

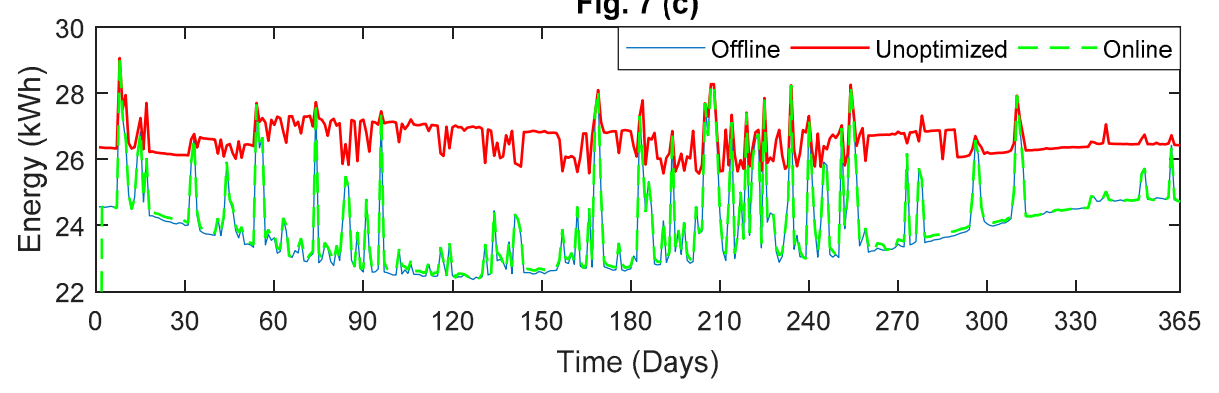

Figure 7. Daily energy demand from the grid throughout the year for the base case and optimized scenarios. (a) for 4-h load shedding (grid unavailable); (b) for 8-h load shedding (grid unavailable); (c) for 12-h load shedding (grid unavailable). 
Fig. 8 (a)

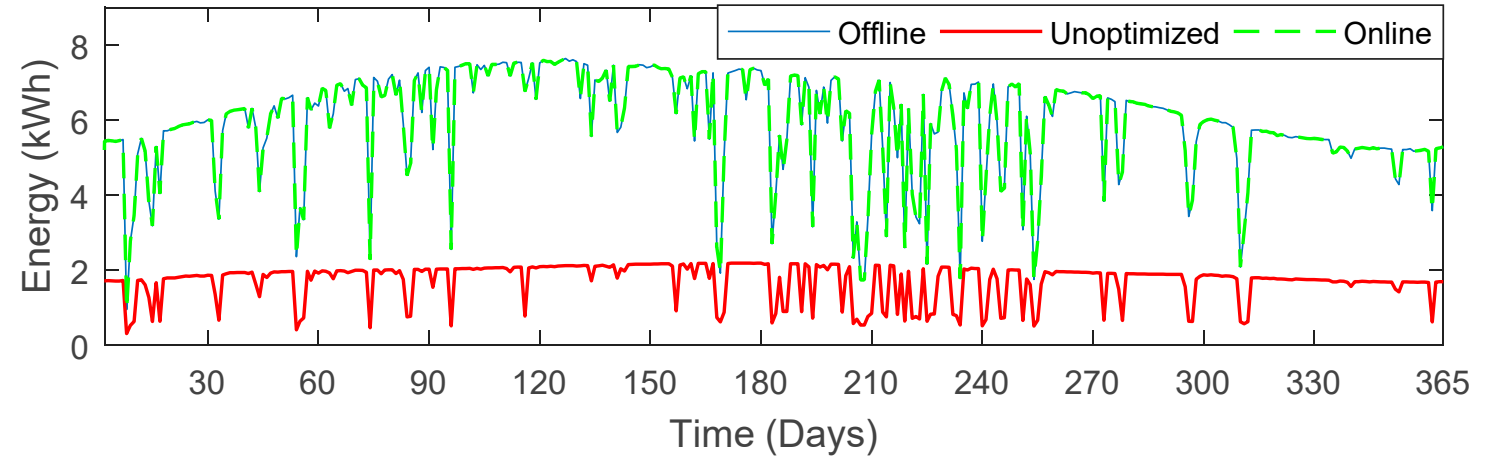

Fig. 8 (b)

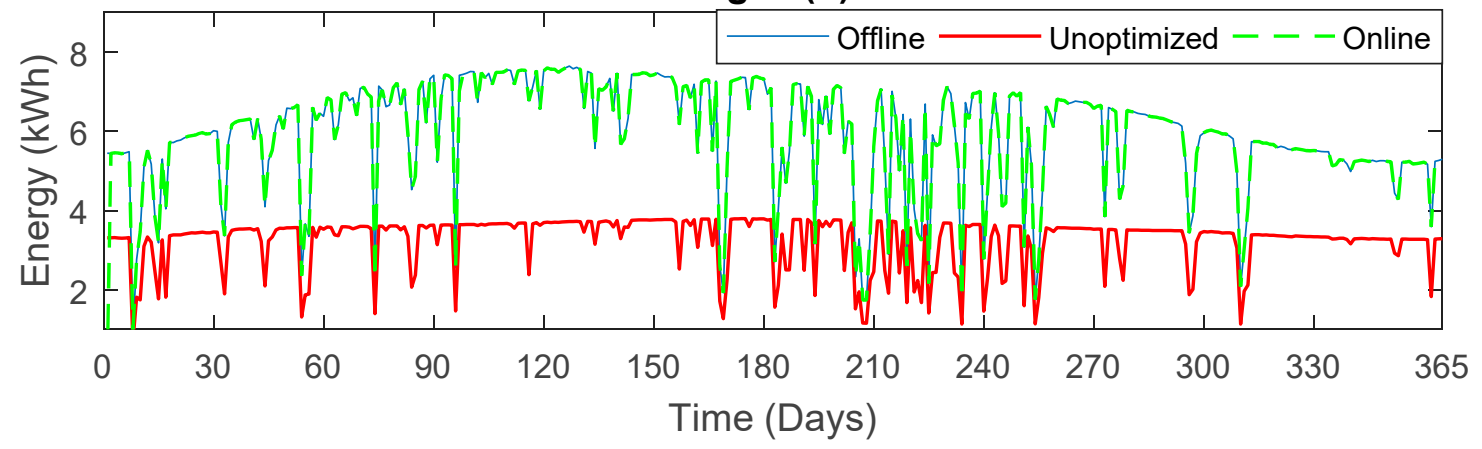

Fig. 8 (c)

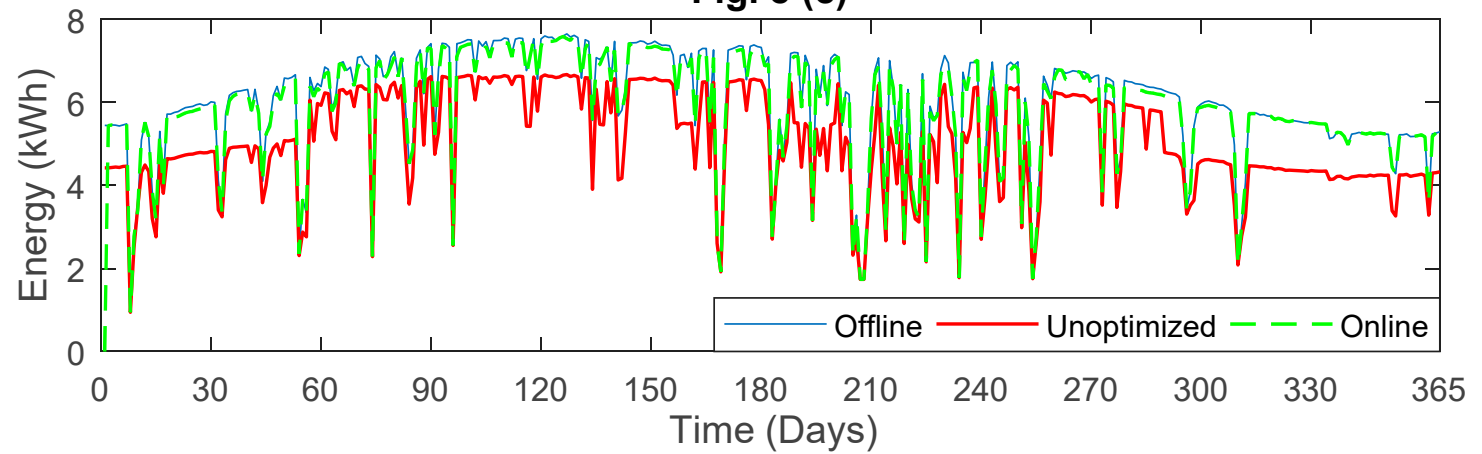

Figure 8. Solar energy utilization for various load shedding scenarios. (a) for 4-h load shedding (grid unavailable); (b) for 8-h load shedding (grid unavailable); (c) for 12-h load shedding (grid unavailable).

Table 1. Percentage reduction in grid load in various intermittence scenarios.

\begin{tabular}{ccc}
\hline Sr. No & No. of Load Shedding Hours & $\begin{array}{c}\text { Percentage Reduction in Grid Load for Optimized } \\
\text { Case Compared to Un-Optimized Case (\%) }\end{array}$ \\
\hline 1 & 0 & 19.6 \\
2 & 4 & 16.5 \\
3 & 8 & 12.3 \\
4 & 12 & 5.8 \\
5 & 16 & 3.2 \\
\hline
\end{tabular}

\section{Open Issues and Challenges}

While there is a definite policy-shift towards net-metering and decentralization of electricity in many developing countries, the grid intermittence is likely to affect consumer energy investment choices. Load shedding (grid outages) are unlikely to go away in developing countries for at least a generation and therefore solutions must be devised to work with the existing settings. A retrofitting 
solution incorporating the presented functionality with existing residential UPS systems would be highly beneficial.

Storage remains the weakest (and the most expensive) link in the current backup systems and more work on the longevity of storage in intermittent scenarios is essential. Batteries generally account for $20 \%-50 \%$ of the upfront system cost in small-scale solar PV backup systems and may even account for up to $75 \%$ in the lifetime cost $[56,57]$. Lead-acid batteries are primarily used for backup applications while lithium ( $\mathrm{Li}$ ) based batteries are now also competing in the residential market (with the advent of Tesla Powerwall and others) [58]. These Li batteries are more efficient and have high cycle life (maximum 5000 cycles) but are generally expensive (200-800 \$/KWh) compared to lead-acid batteries (30-150 \$/KWh). The cycle life of lead-acid batteries is relatively poor (typically 800-1000 cycles) which is a critical concern in the longevity of a backup system [56]. The price of a typical $1 \mathrm{~kW}$ UPS system in developing countries ranges from 180 to $200 \$$ [18]. The cost of the proposed hardware platform for 1 $\mathrm{kW}$ backup system is around $300 \$$. The additional cost (100 \$) of the proposed hardware platform in comparison to conventional UPS system is recovered through the optimal PV utilization by the proposed hardware platform. Our analysis shows that for a typical scenario of 8-h load shedding, the proposed hardware platform is capable to optimally utilize $6 \mathrm{kWh}$ of available PV energy, while un-optimized, market available UPS systems are capable to process only half of the available PV power i.e., $3 \mathrm{kWh}$. Therefore, on average $3 \mathrm{kWh} /$ day of electricity can be reduced from the utility intake. This corresponds to approximately 1000 units $(\mathrm{kWh})$ annual saving. The price of 1 unit of electricity is generally 10 cents $/ \mathrm{kWh}$, which translates into an average saving of almost $100 \$ /$ year. Therefore, the first order cost analysis suggests that the payback time for the proposed system is almost a year and the additional investment on the proposed low-cost hardware platform can be recovered from savings in the utility bill within a year.

Although considerable work is being done in optimizing battery usage in general smart grid and conventional grid-tied settings, the incorporation of optimized charging/discharging routines in backup settings will reduce the system lifetime cost by minimizing battery replacements. Therefore, more work on the aging process and capacity loss minimization of batteries in highly intermittent scenarios would be beneficial. Moreover, optimal system planning and sizing of various systems components including PV size $\left(\mathrm{kW}_{\mathrm{p}}\right)$, battery size $(\mathrm{kWh})$ and distribution conductor size are critical in achieving optimal system gains. Therefore, future focus of the work can be an optimal planning framework for optimal system component size calculation and evaluation of the impact of varying load shedding patterns on optimal system sizing calculations [54].

\section{Conclusions}

Photovoltaic solar energy can have a major role in meeting the growing electricity demands for the developing world. However, its optimum integration in intermittent grid architectures remains a critical research area for its wider uptake. For many developing countries, conventional grid-tied solutions are not optimal due to (a) restrictions in back-feeding to the grid and (b) large grid intermittence where storage is necessary. Thus, the solar PV incorporation in residential intermittent grids is normally limited to aiding the backup power source such as the UPS in households or small suburban industries.

This work identifies key issues with such conventional integration of renewable technology in an intermittent grid environment. It proposes a low-cost hardware platform in which solar PV is capable of not only charging the battery but also powering the critical loads directly (through an inverter). The proposed low-cost hardware platform based on low-cost sensing, real-time monitoring and online algorithm for intelligent decision making, ensures the real-time implementation of optimal decision variables for optimized PV power utilization. Thus, the system can fit into the intermittent grid from both the technology as well as operation perspectives. Results for a 365-day study (for typical settings) verified that gains up to $19.6 \%$ can be achieved through the optimum operation of the proposed system where grid utilization is typically lower compared to conventional approaches. Taking $8 \mathrm{~h}$ of load shedding as an example, the annual energy savings from the grid amounts to be 
more than $1000 \mathrm{kWh}$ for a typical household having $1250 \mathrm{~W}$ average critical load demand $(30 \mathrm{kWh}$ daily energy requirement). Similarly, an energy savings of $16.5 \%$ on energy intake and utility bills can be achieved for $4 \mathrm{~h}$ load shedding scenarios. Almost all the incident available PV power can be optimally processed either for driving the household load or charging the battery. Therefore, local PV generation through these implementations will aid the power sector of many developing countries for achieving a better energy balance between supply and demand.

Author Contributions: Conceptualization, M.N., H.A.K., N.u.H., A.M., and N.A.Z.; methodology, M.N., H.A.K., and N.u.H.; software, M.N. and N.u.H.; validation, M.N.; formal analysis, M.N. and N.u.H.; investigation, M.N.; data curation, M.N., H.A.K., N.u.H.; writing-original draft preparation, M.N., H.A.K.; writing-review and editing, M.N., A.M., T.S., S.M.M. and I.K.; visualization, S.M.M.; supervision, M.N., H.A.K., N.u.H., S.M.M., T.S.; project administration, H.A.K., N.A.Z., and N.u.H.; funding acquisition, I.K.

Funding: The open access publishing fees for this article have been covered by the Texas A\&M University Open Access to Knowledge Fund (OAKFund), supported by the University Libraries and the Office of the Vice President for Research.

Conflicts of Interest: The authors declare no conflicts of interest.

\section{Abbreviations}

\begin{tabular}{ll}
\hline Acronym & Definition \\
\hline MPPT & Maximum Power Point Tracking \\
UPS & Uninterruptable Power Supply \\
FiT & Feed-in-Tariff \\
MPC & Model Predictive Control \\
PSH & Peak Sun Hours \\
TOU & Time of Usage \\
\hline
\end{tabular}

\section{References}

1. International Energy Agency (IEA). Electricity Information 2015; IEA: Paris, France, 2015.

2. Nasir, M.; Zaffar, N.A.; Khan, H.A. Analysis on central and distributed architectures of solar powered DC microgrids. In Proceedings of the Clemson University Power Systems Conference (PSC), Clemson, SC, USA, 8-11 March 2016.

3. Nasir, M.; Khan, H.A.; Hussain, A.; Mateen, L.; Zaffar, N.A. Solar PV-based scalable DC microgrid for rural electrification in developing regions. IEEE Trans. Sustain. Energy 2018, 9, 390-399. [CrossRef]

4. Nasir, M.; Khan, H.A.; Niazi, K.A.K.; Jin, Z.; Guerrero, J.M. Dual-loop Control Strategy applied to PV/battery based Islanded DC microgrids for Swarm Electrification of Developing Regions. Available online: https://www.forskningsdatabasen.dk/en/catalog/2439528045 (accessed on 9 May 2019).

5. Nasir, M.; Jin, Z.; Khan, H.A.; Zaffar, N.A.; Vasquez, J.C.; Guerrero, J.M. A decentralized control architecture applied to dc nanogrid clusters for rural electrification in developing regions. IEEE Trans. Power Electron. 2019, 34, 1773-1785. [CrossRef]

6. Muhammad-Sukki, F.; Abu-Bakar, S.H.; Munir, A.B.; Yasin, S.H.M.; Ramirez-Iniguez, R.; McMeekin, S.G.; Stewart, B.G.; Sarmah, N.; Mallick, T.K.; Rahim, R.A. Feed-in tariff for solar photovoltaic: The rise of Japan. Renew. Energy 2014, 68, 636-643. [CrossRef]

7. Campoccia, A.; Dusonchet, L.; Telaretti, E.; Zizzo, G. An analysis of feed'in tariffs for solar PV in six representative countries of the European Union. Sol. Energy 2014, 107, 530-542. [CrossRef]

8. Nasir, M.; Khan, H.A. Solar photovoltaic integrated building scale hybrid AC/DC microgrid. In Proceedings of the 5th IET International Conference on Renewable Power Generation (RPG), London, UK, 21-23 September 2016.

9. Bacha, S.; Picault, D.; Burger, B.; Etxeberria-Otadui, I.; Martins, J. Photovoltaics in Microgrids: An Overview of Grid Integration and Energy Management Aspects. IEEE Ind. Electron. Mag. 2015, 9, 33-46. [CrossRef]

10. Guerrero, J.M.; Blaabjerg, F.; Zhelev, T.; Hemmes, K.; Monmasson, E.; Jemei, S.; Comech, M.P.; Granadino, R.; Frau, J.I. Distributed Generation: Toward a New Energy Paradigm. IEEE Ind. Electron. Mag. 2010, 4, $52-64$. [CrossRef] 
11. Siraj, K.; Siraj, H.; Nasir, M. Modeling and control of a doubly fed induction generator for grid integrated wind turbine. In Proceedings of the 2014 16th International Power Electronics and Motion Control Conference and Exposition (PEMC), Antalya, Turkey, 21-24 September 2014; pp. 901-906.

12. Zia, F.; Nasir, M.; Bhatti, A.A. Optimization methods for constrained stochastic wind power economic dispatch. In Proceedings of the 2013 IEEE 7th International Power Engineering and Optimization Conference (PEOCO), Langkawi, Malaysia, 3-4 June 2013; pp. 129-133.

13. Krutina, A.; Bartovsky, J. PLC communication in Smart Grid. In Proceedings of the 2014 15th International Scientific Conference on Electric Power Engineering (EPE), Brno, Czech Republic, 12-14 May 2014; pp. 165-168.

14. Wolfram, C.; Shelef, O.; Gertler, P.J. How Will Energy Demand Develop in the Developing World? J. Econ. Perspect. Am. Econ. Assoc. 2012, 26, 119-138. [CrossRef]

15. Shukla, A.K.; Sudhakar, K.; Baredar, P. Renewable energy resources in South Asian countries: Challenges, policy and recommendations. Resour.-Eff. Technol. 2017, 3, 342-346. [CrossRef]

16. Arshad, N.; Ali, U. An analysis of the effects of residential uninterpretable power supply systems on Pakistan's power sector. Energy Sustain. Dev. 2017, 36, 16-21. [CrossRef]

17. Nepal Electricity Authority. Final Report: Nepal India Electricity Transmission and Trade Project; Nepal Electricity Authority: Kathmandu, Nepal, 2016.

18. Ahmad, A.; Saqib, M.A.; Rahman Kashif, S.A.; Javed, M.Y.; Hameed, A.; Khan, M.U. Impact of wide-spread use of uninterruptible power supplies on Pakistan's power system. Energy Policy 2016, 98, 629-636. [CrossRef]

19. Rohankar, N.; Jain, A.; Nangia, O.P.; Dwivedi, P. A study of existing solar power policy framework in India for viability of the solar projects perspective. Renew. Sustain. Energy Rev. 2016, 56, 510-518. [CrossRef]

20. Aguero, J.R.; Khodaei, A.; Masiello, R. The Utility and Grid of the Future: Challenges, Needs, and Trends. IEEE Power Energy Mag. 2016, 14, 29-37. [CrossRef]

21. Starke, M.; Tolbert, L.M.; Ozpineci, B. AC vs. DC distribution: A loss comparison. In Proceedings of the 2008 IEEE/PES Transmission and Distribution Conference and Exposition, Chicago, IL, USA, 21-24 April 2008; pp. 1-7.

22. Batra, N.; Gulati, M.; Singh, A.; Srivastava, M.B. It's Different: Insights into home energy consumption in India. In Proceedings of the 5th ACM Workshop on Embedded Systems For Energy-Efficient Buildings, Rome, Italy, 11-15 November 2013; pp. 1-8.

23. Hossain, M.; Hossain, S.; Uddin, M. Renewable energy: Prospects and trends in Bangladesh. Renew. Sustain. Energy Rev. 2017, 70, 44-49. [CrossRef]

24. Numbi, B.; Malinga, S. Optimal energy cost and economic analysis of a residential grid-interactive solar PV system-case of eThekwini municipality in South Africa. Appl. Energy 2017, 186, 28-45. [CrossRef]

25. Ansari, B.; Shi, D.; Sharma, R.; Simoes, M.G. Economic analysis, optimal sizing and management of energy storage for PV grid integration. In Proceedings of the 2016 IEEE/PES Transmission and Distribution Conference and Exposition (T\&D), Dallas, TX, USA, 3-5 May 2016; pp. 1-5.

26. Arcos-Aviles, D.; Pascual, J.; Marroyo, L.; Sanchis, P.; Guinjoan, F. Fuzzy logic-based energy management system design for residential grid-connected microgrids. IEEE Trans. Smart Grid 2016, 9, 530-543. [CrossRef]

27. Zhou, B.; Li, W.; Chan, K.W.; Cao, Y.; Kuang, Y.; Liu, X.; Wang, X. Smart home energy management systems: Concept, configurations, and scheduling strategies. Renew. Sustain. Energy Rev. 2016, 61, 30-40. [CrossRef]

28. Geem, Z.W.; Yoon, Y. Harmony search optimization of renewable energy charging with energy storage system. Int. J. Electr. Power Energy Syst. 2017, 86, 120-126. [CrossRef]

29. Pascual, J.; Barricarte, J.; Sanchis, P.; Marroyo, L. Energy management strategy for a renewable-based residential microgrid with generation and demand forecasting. Appl. Energy 2015, 158, 12-25. [CrossRef]

30. Wang, Y.; Lin, X.; Pedram, M. A near-optimal model-based control algorithm for households equipped with residential photovoltaic power generation and energy storage systems. IEEE Trans. Sustain. Energy 2016, 7, 77-86. [CrossRef]

31. Sun, C.; Sun, F.; Moura, S.J. Nonlinear predictive energy management of residential buildings with photovoltaics \& batteries. J. Power Sources 2016, 325, 723-731.

32. Anvari-Moghaddam, A.; Guerrero, J.M.; Vasquez, J.C.; Monsef, H.; Rahimi-Kian, A. Efficient energy management for a grid-tied residential microgrid. IET Gener. Transm. Distrib. 2017, 11, 2752-2761. [CrossRef]

33. Zsiborács, H.; Hegedû́sné Baranyai, N.; Vincze, A.; Háber, I.; Pintér, G. Economic and technical aspects of flexible storage photovoltaic systems in europe. Energies 2018, 11, 1445. [CrossRef] 
34. Pintér, G.; Baranyai, N.; Wiliams, A.; Zsiborács, H. Study of photovoltaics and LED energy efficiency: Case study in Hungary. Energies 2018, 11, 790. [CrossRef]

35. Perea-Moreno, A.-J.; Hernandez-Escobedo, Q.; Garrido, J.; Verdugo-Diaz, J. Stand-Alone Photovoltaic System Assessment in Warmer Urban Areas in Mexico. Energies 2018, 11, 284. [CrossRef]

36. Nasir, M.; Khan, H.A.; Zaffar, N.A.; Vasquez, J.C.; Guerrero, J.M. Scalable Solar dc Micrigrids: On the Path to Revolutionizing the Electrification Architecture of Developing Communities. IEEE Electrif. Mag. 2018, 6, 63-72. [CrossRef]

37. Martins, R.; Hesse, H.; Jungbauer, J.; Vorbuchner, T.; Musilek, P. Optimal component sizing for peak shaving in battery energy storage system for industrial applications. Energies 2018, 11, 2048. [CrossRef]

38. Bhattacharjee, V.; Khan, I. A non-linear convex cost model for economic dispatch in microgrids. Appl. Energy 2018, 222, 637-648. [CrossRef]

39. Rayhan, T.; Hossain, S. Design of a Solar Charge Controller Set Point and Lead Acid Battery Capacity Tester; University of Dhaka: Dhaka, Bangladesh, 2016.

40. Nasir, M.; Zia, M.F. Global maximum power point tracking algorithm for photovoltaic systems under partial shading conditions. In Proceedings of the 2014 16th International Power Electronics and Motion Control Conference and Exposition (PEMC), Antalya, Turkey, 21-24 September 2014; pp. 667-672.

41. Schneider Electric. Available online: https://solar.schneider-electric.com/solution/residential-grid-tie-withbackup-power/ (accessed on 9 May 2019).

42. SMA. Available online: https://www.sma.de/en/products/battery-inverters.html (accessed on 9 May 2019).

43. Hybrid Energy. Available online: https://www.hybrid.energy/\#contact-hybrid-energy-storage-system-1480 (accessed on 9 May 2019).

44. Outback Power. Available online: http://www.outbackpower.com/outback-products/make-the-power/gridinteractive-inverter-chargers/item/vented-gvfx3524 (accessed on 9 May 2019).

45. Avenas, Y.; Dupont, L.; Baker, N.; Zara, H.; Barruel, F. Condition Monitoring: A Decade of Proposed Techniques. IEEE Ind. Electron. Mag. 2015, 9, 22-36. [CrossRef]

46. Khan, H.A.; Pervaiz, S. Technological review on solar PV in Pakistan: Scope, practices and recommendations for optimized system design. Renew. Sustain. Energy Rev. 2013, 23, 147-154. [CrossRef]

47. Solanki, C.S. Solar Photovoltaics: Fundamentals, Technologies and Applications; PHI Learning Pvt. Ltd.: New Delhi, India, 2015.

48. Ross, R.G., Jr.; Smokler, M.I. Flat-Plate Solar Array Project Final Report Engineering Sciences and Reliability; Jet Propulsion Lab.: Pasadena, CA, USA, 1986.

49. Cristaldi, L.; Faifer, M.; Rossi, M.; Ponci, F. A simple photovoltaic panel model: Characterization procedure and evaluation of the role of environmental measurements. IEEE Trans. Instrum. Meas. 2012, 61, 2632-2641. [CrossRef]

50. Zimmermann, U.; Edoff, M. A maximum power point tracker for long-term logging of PV module performance. Photovolt. IEEE J. 2012, 2, 47-55. [CrossRef]

51. Bayod-Rújula, Á.-A.; Cebollero-Abián, J.-A. A novel MPPT method for PV systems with irradiance measurement. Sol. Energy 2014, 109, 95-104. [CrossRef]

52. Usama, M.; Qaiser, M.N.; Khan, H.A. Solar irradiance, wind and temperature monitoring for residential PV applications. In Proceedings of the 2015 IEEE 42nd Photovoltaic Specialist Conference (PVSC), New Orleans, LA, USA, 14-19 June 2015; pp. 1-4.

53. Heinemann, D.; Lorenz, E.; Girodo, M. Forecasting of solar radiation. In Solar Energy Resource Management for Electricity. Generation from Local Level to Global Scale, Nova; Science Publishers: Hauppauge, NY, USA, 2006.

54. Nasir, M.; Iqbal, S.; Khan, H.A. Optimal Planning and Design of Low-Voltage Low-Power Solar DC Microgrids. IEEE Trans. Power Syst. 2018, 33, 2919-2928. [CrossRef]

55. Pervaiz, S.; Khan, H.A. Low irradiance loss quantification in c-Si panels for photovoltaic systems. J. Renew. Sustain. Energy 2015, 7, 013129. [CrossRef]

56. Bashir, N.; Sardar, H.S.; Nasir, M.; Hassan, N.U.; Khan, H.A. Lifetime Maximization of Lead-Acid Batteries in Small Scale UPS and Distributed Generation Systems. In Proceedings of the IEEE PowerTech 17, Manchester, UK, 18-22 June 2017. 
57. Bhakta, S.; Mukherjee, V. Performance indices evaluation and techno economic analysis of photovoltaic power plant for the application of isolated India's island. Sustain. Energy Technol. Assess. 2017, 20, 9-24. [CrossRef]

58. Lin, B.; Wu, W. Economic viability of battery energy storage and grid strategy: A special case of China electricity market. Energy 2017, 124, 423-434. [CrossRef]

(C) 2019 by the authors. Licensee MDPI, Basel, Switzerland. This article is an open access article distributed under the terms and conditions of the Creative Commons Attribution (CC BY) license (http://creativecommons.org/licenses/by/4.0/). 